\title{
Case report. Perioperatieve anticoagulantia voor de behandeling van een vena cava inferior tumor trombus bij patiënten met niercelcarcinoom
}

\author{
Pim J. van Leeuwen ${ }^{1}$ Paul C. M. S. Verhagen ${ }^{1}$
}

Published online: 27 October 2017

(C) The Author(s) 2017. This article is an open access publication.

Samenvatting Een 71-jarige patiënt met een niertumor met uitbreiding in de vena cava inferior ( $\mathrm{VCI}$ ) werd één dag voor de geplande operatiedatum, met uitgebreide longembolieën opgenomen op de intensive care. Trombolyse is ternauwernood succesvol, maar hij wordt toch alsnog geopereerd op een later tijdstip. Naar schatting heeft $4-10 \%$ van de patiënten met een nieuw gediagnosticeerd niercelcarcinoom een tumortrombus in de (VCI). Dit geeft een verhoogde kans op trombo-embolische complicaties. Naar de effectiviteit van perioperatieve anticoagulantia bij patiënten met een lokaal uitgebreid niercelcarcinoom is echter nog geen gerandomiseerd onderzoek verricht. Op basis van expert opinion zijn anticoagulantia (low molecular weight heparins (LMWH) therapeutisch gedoseerd) bij patiënten met een niercelcarcinoom met uitbreiding in de VCI geïndiceerd vanaf het moment van diagnose tot en met drie tot zes maanden na operatieve behandeling. Op basis van een literatuuronderzoek wordt aanbevolen om bij patiënten met een niercelcarcinoom met uitbreiding in de VCI direct te starten met therapeutische antistolling.

Trefwoorden niercelcarcinoom - tumortrombus . longembolie $\cdot$ anticoagulantia

dr. Pim J. van Leeuwen

pimvanleeuwen8@gmail.com

1 afdeling Urologie, Erasmus Medisch Centrum Rotterdam, Rotterdam, Nederland
Case report. Perioperative anticoagulation for the management of an inferior caval tumor thrombus in patients with renal cell carcinoma

\begin{abstract}
A 71-year-old patient was diagnosed with a renal cell carcinoma with extension in the IVC. Patient was admitted to the intensive care one day before his planned surgery because of massive pulmonary embolism. Trombolysis was eventually effective and later a radical nephrectomy was successfully performed. Inferior vena caval (IVC) tumor thrombus occurs in 4-10\% of patients diagnosed with renal cell carcinoma. These patients have an increased risk of venous thromboembolism. There is no randomized trial investigating the role of anticoagulants in this patient group. Based on expert opinion it is advised to start Low Molecular Weight Heparins (LMWH), in a therapeutic dose, at time of diagnosis up to three to six months following surgery. Based on a literature search on this subject immediate treatment with therapeutic LMWH is recommended in patients with a renal cell carcinoma extending in the IVC.
\end{abstract}

Keywords renal cell carcinoma t tumor thrombus . pulmonary embolism $\cdot$ anticoagulants

\section{Introductie}

Het niercelcarcinoom is de meest voorkomende maligne niertumor. In 2016 werden naar schatting 2.300 patiënten gediagnosticeerd met niercelcarcinoom. Naar schatting 980 patiënten overleden in dat jaar aan de gevolgen van niercelcarcinoom. Niercelcarcinomen vormen $2 \%$ van alle oncologische tumoren en $90 \%$ van de maligne niertumoren, waarbij het heldercellig niercelcarcinoom (60-70\%) en het papillaire niercelcarcinoom $(15-30 \%)$ het meest frequent 
voorkomen $[1,2]$. Door frequenter gebruik van beeldvormende technieken worden de tumoren vaker en eerder ontdekt.

Niercelcarcinoom met uitbreiding van een tumortrombus (TT) in de vena cava inferior (VCI) komt naar schatting voor bij 4-10\% van de nieuw gediagnosticeerde patiënten, met in $1 \%$ van de gevallen uitbreiding van de TT tot in het rechteratrium [3]. De geschatte vijfjaarsoverleving van patiënten met een niercelcarcinoom en een TT in de VCI na radicale chirurgie varieert tussen de $26 \%$ en $35 \%$ [1]. De perioperatieve mortaliteit is gecorreleerd met de trombectomie van de VCI en varieert tussen de $5 \%$ en $12 \%$, afhankelijk van de comorbiditeit en de tumorkarakteristieken [4]. Ongeveer 6\% van de patiënten met een TT in de VCI ontwikkelt een perioperatieve longembolie, een serieuze complicatie met een mortaliteitsrisico van $60-75 \%$ [4].

Dit artikel heeft als doel de aandacht te vestigen op de plaats van anticoagulantia bij de optimale behandeling van het lokaal uitgebreid niercelcarcinoom.

\section{Casus}

Een 71-jarige kaukasische man, nooit gerookt, met een body mass index van 26 , werd gediagnosticeerd met een tumor uitgaande van de rechternier, die te zien was op een echografie van het abdomen. Het onderzoek werd uitgevoerd vanwege buikklachten. Zijn voorgeschiedenis vermeldde een miltextirpatie na trauma en was verder onopvallend. Hij gebruikte geen medicatie. Een CT-scan van thorax en abdomen toonde een cT3bNOM0-tumor uitgaande van de rechternier met uitbreiding in de rechter vena renalis

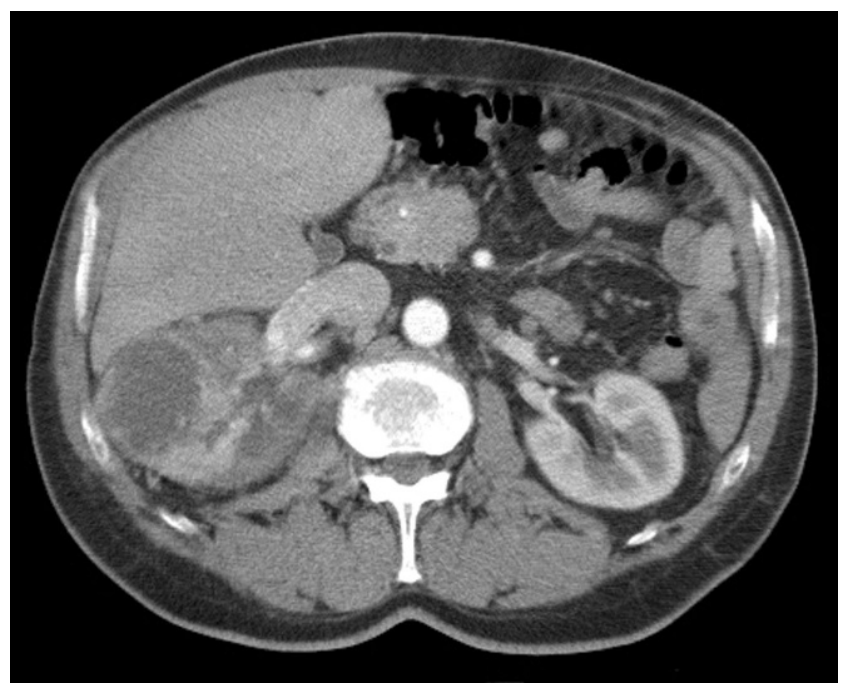

Figuur 1 CT-scan van thorax en abdomen waarop een $5,6 \mathrm{~cm}$ grote cT3bN0M0-tumor te zien is, die uitgaat van de rechternier, met uitbreiding in de rechter vena renalis, en een CVI tot aan de levervenen

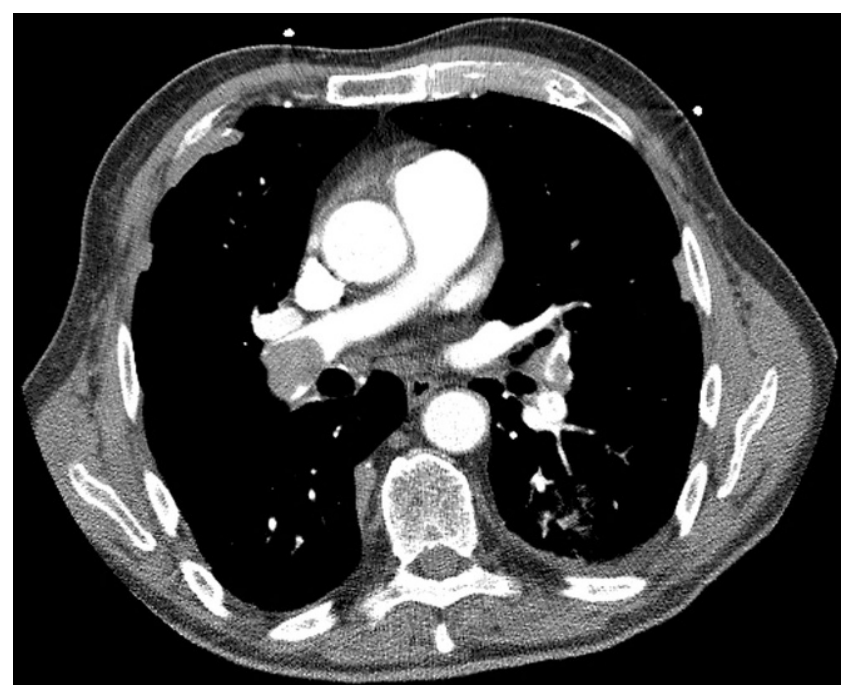

Figuur 2 CT-scan van de thorax toont een uitgebreide centraal gelegen longembolie in beide pulmonaalarteriën, met overbelasting rechts. Zichtbaar zijn een vergrote rechterventrikel en buiging van het septum

en VCI tot aan de levervenen (fig. 1). De patiënt werd gepland voor een radicale nefrectomie met cavotomie. Na een wachttijd van vijf weken meldde hij zich één dag preoperatief met algehele malaise en misselijkheid. Hij werd opgenomen ter observatie. In de nacht werd patiënt acuut respiratoir insufficiënt en opgenomen op de intensive care, waar hij zuurstof kreeg toegediend via een non-rebreathing masker $15 \mathrm{~L} / \mathrm{min}$. Een CT-scan van de thorax toonde uitgebreide longembolieën centraal in beide pulmonaalarteriën (fig. 2). Er werd gestart met trombolyse, waarop hij klinisch goed reageerde. De ingreep werd uitgesteld en na een week werd de patiënt overgeplaatst naar ons centrum. Er volgde een abdominale radicale nefrectomie met cavotomie, waarbij radicale resectie plaatsvond van de rechternier en een TT. Pathologie toonde een heldercellig niercelcarcinoom (diameter 5,8 cm; WHO/ISUP-graad 3) met ingroei in de vena renalis en de renale sinus. Het postoperatief beloop werd gecompliceerd door een dalende hemoglobinewaarde en het ontstaan van een hematoom in het operatiegebied, waarvoor één week postoperatief een re-laparotomie werd uitgevoerd. Hierna trad een geleidelijk herstel op. De antistolling werd gecontinueerd in therapeutische dosering (nadroparine 19.000 IE/dag). Eén jaar na de radicale nefrectomie maakt patiënt het goed. De CT-thorax en abdomen toont geen tekenen van metastasen of lymfadenopathie.

\section{Discussie}

Bij lokaal gevorderde niercelcarcinomen met doorgroei in de centrale vaten is operatieve behandeling de eerste keus. Operatief ingrijpen geeft relatief goede resultaten en kan 
ontwikkeling van een VCI-syndroom voorkomen. In een retrospectieve analyse van Yokom et al. had 30,1\% van de patiënten met een stadium-3- of -4-niercelcarcinoom een veneuze TT [5]. De overleving is afhankelijk van het niveau tot waar de tumortrombus in de centraal veneuze vaten reikt. Zo geeft doorgroei tot in de vena renalis een vijfjaarsoverleving van 50-55\%, doorgroei tot in de vena cava inferior een vijfjaarsoverleving van 26-35\% en doorgroei tot in het rechteratrium een vijfjaarsoverleving van $0-20 \%$ [6].

Een TT in de vena renalis die tot in de VCI reikt, heeft invloed op de vasculaire wand en de veneuze flow, wat kan leiden tot trombose. Het tumoroppervlak kan zelf ook trombogeen zijn. Yokom et al. onderzochten of veneuze TT in de wachttijd ( $<21$ dagen) voor een nefrectomie vanwege niercarcinoom een risico vormde voor het ontwikkelen van een veneuze trombo-embolie (VTE), diepveneuze trombose (DVT) of een longembolie (LE) en toonden aan dat dit risico bij patiënten met veneuze TT inderdaad significant verhoogd was [5]. Daarnaast hebben kankerpatiënten in het algemeen een verhoogd risico op het ontwikkelen van een VTE [7-9]. Bij een gemetastaseerde maligniteit is VTE vaak de reden van overlijden en ook is VTE een onafhankelijke risicofactor voor mortaliteit bij ziekenhuispatiënten [10]. Verondersteld wordt dat bij kankerpatiënten verschillende mechanismen een rol spelen, zoals activatie van de stollingscascade door de tumorcel zelf, specifieke effecten van bloedplaatjes, witte bloedcellen en/of endotheelcellen, en hoge concentraties van verschillende cytokines (interleukine-1, tumornecrosefactor, vascular endothelial growth factor) $[11,12]$. Het geheel kan resulteren in een toename van stollingsbevorderende eiwitten of afname van eiwitten die normaliter de afbraak van de trombus bewerkstellingen. Kankercellen zelf kunnen eiwitten produceren die de stolling rechtstreeks op gang brengen of bevorderen [12]. Een voorbeeld hiervan is weefselfactor (tissue factor; TF), de initiator van de stolling, of het zogeheten cancer procoagulant-eiwit. Veel tumoren hebben een verhoogde expressie van TF op het oppervlak van tumorcellen. TF bevordert immers niet alleen de bloedstolling, maar speelt ook een rol bij metastasering en angiogenese, twee processen die sterk bepalend zijn voor de mate waarin een tumor zich agressief gedraagt [11]. Patiënten met een lokaal gevorderd niercelcarcinoom met doorgroei in de centrale vaten hebben dus een verhoogd risico op VTE, waarbij de belangrijkste oorzaken gelegen zijn in biologische activiteit van de tumor, veranderingen in de vaatwand en hemodynamische veranderingen.

Bij ons literatuuronderzoek vonden wij slechts een enkele studie naar het resultaat van een pre- en postoperatieve anticoagulantiabehandeling bij patiënten met een niercelcarcinoom en een TT in de VCI. Er is nog geen gerandomiseerd onderzoek uitgevoerd naar de effectiviteit van perioperatieve anticoagulantia bij patiënten met een lokaal uitgebreid niercelcarcinoom. Eén studie naar de perioperatieve behandeling van deze patiëntengroep is noemenswaard. Dit is de beschrijvende review van Woodruff et al., waarin aanbevelingen worden geformuleerd op basis van de literatuur en expertopinies, onder meer over het toedienen van anticoagulantia in de vorm van low molecular weight heparin (LMWH) aan alle patiënten bij wie geen contra-indicaties bestaan voor anticoagulantia [13]. Hun aanbeveling luidt dat met LMWH in therapeutische dosis wordt gestart op het moment van de diagnose niercelcarcinoom met TT in de VCI, waarbij de laatste dosis 24 uur voor aanvang van de operatie wordt toegediend. In de behandelrichtlijnen voor niercelcarcinoom van de Nederlandse Vereniging voor Urologie, de European Association of Urology en de American Urology Association worden geen uitspraken gedaan over het gebruik van perioperatieve anticoagulantia bij niercelcarcinoom met een TT in de VCI $[14,15]$. In de Mayo Clinic in de Verenigde Staten worden patiënten met een TT in de VCI wél preoperatief behandeld met anticoagulantia [16]. Een LMWH wordt verkozen op basis van het level-1bewijs, dat LMWH het risico op een recidief-VTE verlaagt, zonder een verhoogd risico op ernstige bloedingen en met een significant langere overall overleving van patiënten met een maligniteit die worden behandeld met een LMWH in vergelijking met patiënten die worden behandeld met warfarine $[17,18]$.

De hematologische literatuur beschikt over uitgebreide data en aanbevelingen voor gebruik van anticoagulantia bij kankerpatiënten. Lee et al. hebben aangetoond dat LMWH de beste vorm van antistolling is voor de initiële en langetermijnbehandeling van VTE bij patiënten met een maligniteit [17]. Dit is gebaseerd op het level-1-bewijs dat LMWH een statistisch significant lager risico geeft op een recidief veneuze trombus, geen verhoogd risico op bloedingen en een verbeterde overall survival [17]. De Nederlandse richtlijn 'Optimale profylaxe voor symptomatische VTE voor chirurgische patiënten' adviseert om LMWH postoperatief te geven in een geregistreerde profylactische dosis, aan alle patiënten na oncologische resecties in de thorax, het abdomen of het kleine bekken. De LMWH dient zes uur postoperatief gestart te worden en gegeven te worden met een verlengde duur van vier weken voor patiënten die een ingreep ondergaan met een hoog tromboserisico en risicofactoren voor VTE, zoals een BMI $>30$ of een VTE in de voorgeschiedenis.

Woodruff et al. adviseert op basis van expert opinion tot zes maanden na de operatie LMWH te geven in therapeutische dosis. Ter vergelijkig, na (chirurgische) behandeling van DVT worden anticoagulantia tot minimaal drie maanden na behandeling gegeven. Patiënten na nefrectomie met resectie van een TT in de VCI hebben een verhoogd risico op een VTE in de maanden na de operatie [19]. Binnen 
Tabel 1 Protocol pre- en postoperatieve anticoagulantia bij patiënten met een lokaal gevorderd niercelcarcinoom met TT in de VCI. [13]

\begin{tabular}{lc}
\hline preoperatief protocol & postoperatief protocol \\
\hline - LMWH bij alle patiënten zonder contra-indicatie voor anticoagu- & - LMWH bij alle patiënten zonder contra-indicatie voor anticoagu- \\
lantia & lantia \\
- start direct na diagnose TT in VCI op de polikliniek & - start 48 uur na chirurgie, tenzij verdenking op een actieve bloeding \\
- LMWH in therapeutische dosis & - duur: 3-6 maanden bij patiënten bij wie de tumor radicaal is ver- \\
- laatste dosis LMWH 24 uur voor chirurgie & wijderd; pas de duur eventueel aan bij patiënten met incomplete \\
& resectie, een longembolie of een metastase \\
\hline
\end{tabular}

$T T$ tumortrombus, $V C I$ vena cava inferior.

deze groep hebben patiënten met een residu-TT een significant verhoogd risico op een VTE tot twee jaar na de operatie (HR 8,7; $95 \%-\mathrm{BI}=1,7-43,4)$ [20]. Het lijkt dus het beste om de postoperatieve behandeling met LMWH per patiënt te bepalen, waarbij geadviseerd kan worden om patiënten na een irradicale resectie van de TT langer met een LMWH te behandelen. De aanbevelingen voor pre- en postoperatieve anticoagulantia bij patiënten met een lokaal gevorderd niercelcarcinoom met TT in de VCI zijn samengevat in tab. 1.

Als laatste lijkt de tijd van diagnose tot aan de operatie van essentieel belang bij de behandeling van patiënten met niercelcarcinoom en een TT in de VCI. In de door ons beschreven casus bleek een wachttijd van vijf weken te lang. Deze bevinding wordt echter niet ondersteund door de literatuur. Bij patiënten met een niercelcarcinoom van stadium II of hoger leidde de wachttijd na de diagnose (4 weken of 1-3 maanden) niet tot verschillen in pathologische stadiëring of recidiefvrije overleving [21].

\section{Conclusies}

Patiënten met niercelcarcinoom en een TT in de VCI hebben een relatief hoog risico op perioperatieve morbiditeit en mortaliteit. De perioperatieve zorg van deze groep patiënten varieert tussen klinieken, mede door het gebrek aan goede prospectieve studies en aanbevelingen in de huidige richtlijnen. Wij zijn van mening dat een patiënt met een niercelcarcinoom en een TT in de VCI perioperatief behandeld moeten worden met anticoagulantia. Preoperatief dienen anticoagulantia, bij voorkeur LMWH in therapeutische dosis, te worden gestart na de diagnose op de polikliniek en te worden gecontinueerd tot 24 uur voor de operatie als er geen contra-indicaties voor anticoagulantia zijn. Postoperatief dient LMWH in therapeutische dosis gegeven te worden gedurende drie tot zes maanden.

Open Access This article is distributed under the terms of the Creative Commons Attribution 4.0 International License (http:// creativecommons.org/licenses/by/4.0/), which permits unrestricted use, distribution, and reproduction in any medium, provided you give appropriate credit to the original author(s) and the source, provide a link to the Creative Commons license, and indicate if changes were made.

\section{Literatuur}

1. Znaor A, Lortet-Tieulent J, Laversanne M, Jemal A, Bray F. International variations and trends in renal cell carcinoma incidence and mortality. Eur Urol. 2015;67(3):519-30.

2. Siegel RL, Miller KD, Jemal A. Cancer statistics. CA Cancer J Clin. 2017;67(1):7-30.

3. Blute ML, Leibovich BC, Lohse CM, et al. The Mayo Clinic experience with surgical management, complications and outcome for patients with renal cell carcinoma and venous tumour thrombus. BJU Int. 2004;94(1):33-41.

4. Shuch B, Larochelle JC, Onyia T, et al. Intraoperative thrombus embolization during nephrectomy and tumor thrombectomy: critical analysis of the University of California-Los Angeles experience. J Urol. 2009;181(2):492-8. discussion 8-9.

5. Yokom DW, Ihaddadene R, Moretto $P$, et al. Increased risk of preoperative venous thromboembolism in patients with renal cell carcinoma and tumor thrombus. J Thromb Haemost. 2014;12(2):169-71.

6. Pouliot F, Shuch B, Larochelle JC, et al. Contemporary management of renal tumors with venous tumor thrombus. J Urol. 2010;184(3):833-41. quiz 1235.

7. Noble SI, Shelley MD, Coles B, et al. Management of venous thromboembolism in patients with advanced cancer: a systematic review and meta-analysis. Lancet Oncol. 2008;9(6):577-84.

8. Noble S, Pasi J. Epidemiology and pathophysiology of cancer-associated thrombosis. Br J Cancer. 2010;102(Suppl 1):S2-S9.

9. Lee AY, Levine MN. Venous thromboembolism and cancer: risks and outcomes. Circulation. 2003;107(23 Suppl 1):I17-I21.

10. Khorana AA, Francis CW, Culakova E, et al. Thromboembolism is a leading cause of death in cancer patients receiving outpatient chemotherapy. J Thromb Haemost. 2007;5(3):632-4.

11. Nijziel MR, Oerle R van, Hillen HF, Hamulyak K. From Trousseau to angiogenesis: the link between the haemostatic system and cancer. Neth J Med. 2006;64(11):403-10.

12. Poon RT, Fan ST, Wong J. Clinical implications of circulating angiogenic factors in cancer patients. J Clin Oncology. 2001;19(4):1207-25.

13. Woodruff DY, Veldhuizen $P$ van, Muehlebach G, et al. The perioperative management of an inferior vena caval tumor thrombus in patients with renal cell carcinoma. Urol Oncol. 2013;31(5):517-21.

14. Campbell S, Uzzo RG, Allaf ME, Bass EB, Cadeddu JA, Chang A, et al. Renal mass and localized renal cancer: AUA guideline. J Urol. 2017;198(3):520-9.

15. Ljungberg B, Bensalah K, Canfield S, Dabestani S, Hofmann F, Hora M, et al. EAU guidelines on renal cell carcinoma: 2014 update. Eur Urol. 2015;67(5):913-24.

16. Psutka SP, Leibovich BC. Management of inferior vena cava tumor thrombus in locally advanced renal cell carcinoma. Ther Adv Urol. 2015;7(4):216-29.

17. Lee AY, Levine MN, Baker RI, et al. Low-molecular-weight heparin versus a coumarin for the prevention of recurrent venous throm- 
boembolism in patients with cancer. N Eng J Med. 2003;349(2): 146-53.

18. Lyman GH, Khorana AA, Kuderer NM, et al. Venous thromboembolism prophylaxis and treatment in patients with cancer: American Society of Clinical Oncology clinical practice guideline update. J Clin Oncol. 2013;31(17):2189-204.

19. Chew HK, Wun T, Harvey D, Zhou H, White RH. Incidence of venous thromboembolism and its effect on survival among patients with common cancers. Arch Intern Med. 2006;166(4):458-64.
20. Ihaddadene R, Yokom DW, Le Gal G, et al. The risk of venous thromboembolism in renal cell carcinoma patients with residual tumor thrombus. J Thromb Haemost. 2014;12(6):855-9.

21. Kim KH, You D, Jeong IG, et al. The impact of delaying radical nephrectomy for stage II or higher renal cell carcinoma. J Cancer Res Clin Oncol. 2012;138(9):1561-7.

dr. Pim J. van Leeuwen uroloog

dr. Paul C.M.S. Verhagen uroloog 